\title{
Lower Pole of Kidney
}

National Cancer Institute

\section{Source}

National Cancer Institute. Lower Pole of Kidney. NCI Thesaurus. Code C93180.

The pole of the kidney located in the lowest region of the kidney. 